\title{
MATERIALIZAR CIDADES INVISÍVEIS: inventando caminhos criativos no ensino técnico em comunicação visual
}

\author{
Ana Paula Freitas Margarites \\ IFSul - Instituto Federal de Educação Ciência e Tecnologia Sul-riograndense \\ anamargarites@gmail.com
}

Resumo: Este artigo fala sobre a experiência de uma professora ao conduzir, junto a uma turma de estudantes do Curso Técnico em Comunicação Visual do IFSul - Pelotas - Brasil, um projeto experimental de desenvolvimento de identidades visuais na disciplina intitulada Laboratório de Criatividade. Neste caso, foram utilizados textos do livro Cidades Invisíveis, do escritor Ítalo Calvino, como ponto de partida para a criação de marcas e peças gráficas para diferentes cidades inexistentes descritas pelo autor. Breves entrevistas realizadas com os estudantes dão pistas a respeito de como o processo correu de forma rizomática, contaminado por afetações e trânsitos. Em um exercício que promovia a utilização de um texto literário como briefing para um projeto, os estudantes foram estimulados a repensar e construir seus próprios processos criativos, resultando em peças que apresentam grande diversidade de linguagens.

Palavras-chave: design gráfico, ensino técnico, metodologia, criatividade.

\begin{abstract}
This article talks about the experience of a teacher while driving, along with a group of students from the Technical Course in Visual Communication IFSul - Pelotas - Brazil, an experimental project for developing visual identities in the course entitled Creativity Lab. In this case, the highly acclaimed book Invisible Cities, written by Italo Calvino, was used as a starting point for branding and graphic elements development for different nonexistent cities described by the author. Brief interviews with students give clues as to how the process ran in a rhizomatic way contaminated by affectations and transits. In an exercise that promoted the use of a literary text as a briefing for a project, students were encouraged to rethink and build their own creative processes, resulting in pieces that use a great diversity of languages.
\end{abstract}

Keywords: graphic design, technical education, methodology, creativity. 


\section{INTRODUÇÃO}

Parece não haver dúvidas de que a educação profissional no Brasil buscou manter-se atenta às transformações operadas no âmbito do sistema produtivo e de serviços, especialmente no que diz respeito às profundas modificações causadas pela globalização e consolidação de um sistema econômico regulado pelo mercado. Sobre tais aspectos, um grande número de estudos nas áreas da educação, sociologia e economia debruçou-se, especialmente durante os anos 90 e primeira década do século $\mathrm{XXI}$. Entre as consequências mais concretas desta abordagem, destaca-se "uma forte ênfase no treinamento dirigido aos setores operacionais por parte de empresas em processo de adoção de inovações tecnológicas de base física e operacional" (FERRETI, 1997).

Neste contexto, a educação técnica configurou-se como um local privilegiado para a formação deste trabalhador orientado às necessidades de um mercado que determina, em níveis minuciosos, quais atributos cognitivos e comportamentais espera-se de um recém-formado apto à atuação profissional. As Escolas Técnicas Federais brasileiras - muitas das quais incluíam cursos de Desenho Industrial operaram, especialmente na década de 90, dentro desta lógica.

As políticas brasileiras de ensino técnico sofrem uma reconfiguração importante com a fundação dos Institutos Federais, em 2008. De acordo com o texto da Lei no. 11.892, os IFs são "instituições de educação superior, básica e profissional, pluricurriculares e multicampi, especializadas na oferta de educação profissional e tecnológica nas diferentes modalidades de ensino". Quanto ao desenho curricular, os IFs ofertam educação básica, notadamente em cursos de ensino médio integrado à educação profissional técnica de nível médio, ensino técnico em geral (em modalidade pós-ensino médio), cursos superiores de tecnologia, licenciatura e bacharelado em áreas em que a ciência e tecnologia são determinantes. Desta forma, a política que institui os IFs os coloca em papel de importante ator no desenvolvimento tecnológico nacional principalmente no que tange à pesquisa aplicada, mas ainda reforçando a formação do sujeito trabalhador (FAVRETTO et al., 2013).

O campus Pelotas do Instituto Federal Sul-Riograndense origina-se de uma das mais tradicionais instituições de ensino técnico no Brasil: a Escola Técnica de Pelotas, fundada em 1942. Estabelecido em 1994, o antigo curso de Desenho Industrial originou dois cursos técnicos de nível médio (Comunicação Visual e Design de Interiores), dois de nível técnico pós-médio (Comunicação Visual e Design de Móveis, ambos em extinção) e um bacharelado em Design. No caso específico dos cursos de design do IFSul Pelotas, configura-se um território interessante: o corpo docente de todos os cursos é composto pelos mesmos professores, que transitam "verticalmente" - ou seja, do curso técnico médio ao curso superior - dentro de suas áreas de conhecimento e interesse.

Enquanto grande parte das disciplinas da grade curricular dos cursos técnicos pós-médio preocupam-se fundamentalmente em aproximar o estudante do saber técnico relacionado ao campo de trabalho, o Laboratório de Criatividade promove, de acordo com sua ementa, "experimentações que envolvam leitura de imagens e processos de criação contemporâneos". Tal disciplina, oferecida no quarto (e último) 
semestre do curso Técnico em Comunicação Visual, é tida como um espaço para exploração de diferentes processos criativos, sem as limitações tradicionais impostas por propostas de trabalho com briefings realistas (e muitas vezes, reais) trazidos pelos professores de outros temas.

A partir da vontade de explorar, junto aos estudantes, outras possibilidades de formação de processos criativos, surgiu a ideia de realizar o Projeto Cidades Invisíveis durante o segundo semestre do ano de 2013. Cada um dos estudantes que integravam a turma recebeu como briefing um dos capítulos do livro "Cidades Invisíveis", do escritor Ítalo Calvino. A partir daí, o projeto incluía a criação de uma identidade visual e algumas peças gráficas para uma cidade que existe apenas na literatura.

Se entre as ênfases do curso técnico continua a preocupação com a formação de uma mão-de-obra atenta às demandas do mercado mundial capitalista, então como estimular nos estudantes o desejo de resistir e criar? No caso aqui apresentado, buscou-se a valorização da experiência sensível, em que conceitos rígidos e verdades dão espaço a construções individuais e coletivas. Para DELEUZE (1999), a ideia de "conceito" expressa um acontecimento, e não uma essência; reflete multiplicidades criadas a partir da experiência, e não uma verdade única. Assim, o processo de design foi visto, neste caso, não como a procura pela "solução de um problema", mas como o processo ativo e produtivo de inventar mundos.

\section{DESENVOLVIMENTO}

O livro cidades Invisíveis, do escritor italiano Italo Calvino, foi a "matéria-prima" a partir da qual se desenrolou o projeto durante o semestre. Tal obra, publicada no ano de 1972, narra ficcionalmente as viagens de Marco Polo ao oriente, constituindose como um relato ao imperador mongol Kublai Kan, que desconhecia a vastidão do seu próprio império e as cidades onde era soberano. As diversas cidades visitadas por Marco Polo - todas com nomes femininos - são descritas em pequenos textos, nomeados "As Cidades e a Memória", "As Cidades e o Desejo", "As Cidades e os Símbolos" etc. Não existe uma narrativa que atravesse e conecte as cidades; no caso das Cidades Invisíveis, não importa a viagem, mas apenas o(s) destino(s).

Este procedimento equivale a "viajar" pelo território da literatura, por itinerários já esgotados, em que todas as histórias já foram contadas até o limite da saturação e só é possível inventariar, revisitar, reciclar. A tradição é estocagem, espécie de arquivo, que possibilita uma arte combinatória, num jogo de deslocamentos, inversões, substituições infinitas (GOMES, 1999, p.25).

O trabalho de Calvino, dentro deste contexto, foi abordado como se fosse uma espécie de "briefing com licença poética" (conforme descrito de um dos estudantes). Cada um dos integrantes da turma recebeu, por sorteio, um texto sobre uma cidade. Em um primeiro momento, foi solicitado aos estudantes que desenvolvessem duas peças gráficas: um cartão postal medindo $10 \times 15 \mathrm{~cm}$ e uma ilustração / retrato em formato a3 que representasse um morador qualquer da cidade. Em seguida, foram desenvolvidas as marcas e, como última parte do projeto, um cartaz que servisse de peça de divulgação da cidade ou de um evento que ocorresse em tal localidade (como uma feira, festival etc.). 
Ao solicitar aos estudantes que elaborassem o cartão postal e a ilustração do morador da cidade, a intenção era estimulá-los a começarem a materializar um repertório visual que, mais adiante, viesse a auxiliá-los a compor a identidade visual da cidade. É importante frisar aqui que não foi definida qual técnica deveria ser utilizada na execução do trabalho; como resultado desta liberdade de criação, foram apresentadas peças feitas à mão, em fotografia, com montagens digitalmente geradas e também com softwares de ilustração digital.

$\mathrm{Na}$ elaboração das primeiras peças gráficas, os estudantes tiveram a oportunidade de pensar em cores, texturas e formas que compunham um conjunto de elementos associados àquela cidade, de maneira que o processo posterior, de desenvolvimento da identidade visual propriamente dita, já pudesse partir de linguagem experimentada por eles. Os processos de criação das primeiras peças e da marca, de acordo com os próprios estudantes, foram os mais diversos, sempre enriquecidos pelo próprio repertório dos estudantes. Enquanto um deles utilizou a direção de arte de um filme como inspiração e ponto de partida para a criação da linguagem gráfica das peças, outro preferiu partir de sua predileção pelo desenho à mão, combinado com seu interesse por jogos do tipo RPG. Tal processo, onde a livre associação entre ideias cumpriu papel de destaque, se assemelha ao processo descrito por Ostrower, quando falando da criatividade infantil:

Nas crianças, a criatividade se manifesta em todo seu fazer solto, difuso, espontâneo, imaginativo, no brincar, no sonhar, no associar, no simbolizar, no fingir da realidade e que no fundo não é senão o real. Criar é viver, para a criança (OSTROWER, 1977, p. 127).

A diversidade de linguagens e elementos presentes nas peças criadas pelos estudantes dá pistas a respeito de como o processo correu contaminado por afetações e trânsitos, de forma rizomática. Para Deleuze e Guatarri (1997), um rizoma é um sistema conceitual aberto, relacionado a circunstâncias e não mais a essências. Em um sistema conceitual rizomático, um universo de referências pode vir de qualquer parte: enquanto designer, um sujeito pode ser circunstancialmente afetado pelo cinema, pela fotografia, por uma conversa, uma música, um grafite, uma receita, uma paisagem, um texto literário ou qualquer coisa que o afete. Para os autores, não existe um pressuposto que sustente todo o conhecimento, e que se ramifica infinitamente em direção à verdade. A estrutura do conhecimento assume forma fascicular, em que não há ramificações, e sim pontos que se originam de qualquer parte, e se dirigem para quaisquer pontos. O conceito de rizoma surge, assim, em oposição à forma segmentada de se conceber a realidade, bem como ao modo positivista de se construir conhecimento. O processo de design, neste caso, não é mais visto como "solução de um problema", mas como uma invenção possível a partir de um desejo.

Quando questionado a respeito do processo de desenvolvimento da marca e da aplicabilidade dos elementos anteriormente criados, um dos estudantes afirmou:

Na marca eu sintetizei muito dos pensamentos que usei no cartão postal e personagem. Elas, mais a narrativa que veio junto e um pouco de acaso ajudaram a marca a seguir determinado rumo que chegou, no final. (Estudante 1) 
Outro estudante comenta que utilizou o texto como um cenário, de onde, tal qual um detetive, buscou extrair "pistas" que o ajudassem a localizar a cidade física e temporalmente:

Criar as peças antes me ajudou muito a pensar na marca, uma vez que a idealização de ambos só foi possível após inúmeras leituras do texto, após analisar cada descrição de Calvino. Os substantivos e adjetivos utilizados pelo autor permitiram o posicionamento de Melânia no tempo e, a partir disso, a busca de características visuais, como a paleta de cores aplicada na identidade. Ainda, todo esse pensamento originou a dependência entre os itens do símbolo, que representam a ligação entre os moradores da cidade. (Estudante 2)

O processo criativo deste estudante partiu, principalmente, do seguinte trecho do texto de Calvino:

\footnotetext{
- Mas qual é a pedra que sustenta a ponte? - pergunta Kublai Khan.

- A ponte não é sustentada por esta ou aquela pedra - Responde Marco Polo -, mas pela curva do arco que elas formam.

Kublai Khan permanece em silêncio, reetindo. Depois acrescenta:

- Por que falar das pedras? Só o arco me interessa.

Polo responde:

- Sem pedras o arco não existe. (CALVINO, 2003, p.79).
}

Esta curta passagem aparece, no texto de Calvino, como uma observação feita imediatamente depois de encerrada a descrição da cidade de Melânia. Em tal cidade, de acordo com o estudante, "todas as vezes que se vai à praça encontra-se um pedaço de diálogo. Ao retornar após um longo tempo, reencontra-se a continuação do mesmo diálogo, desta vez com personagens novas ou reposicionadas, ou com um dialogador mantendo simultaneamente dois ou mais papéis". Combinando os dois textos, o estudante pensou os diálogos como as pedras da ponte; são eles que sustentam a existência da cidade.

A marca da cidade, assim, compõe-se de um símbolo que representa o encaixe das pedras interdependentes na ponte, e que, ao mesmo tempo, imita a curva da letra "e" do logotipo, estabelecendo a relação entre ponte e palavra.

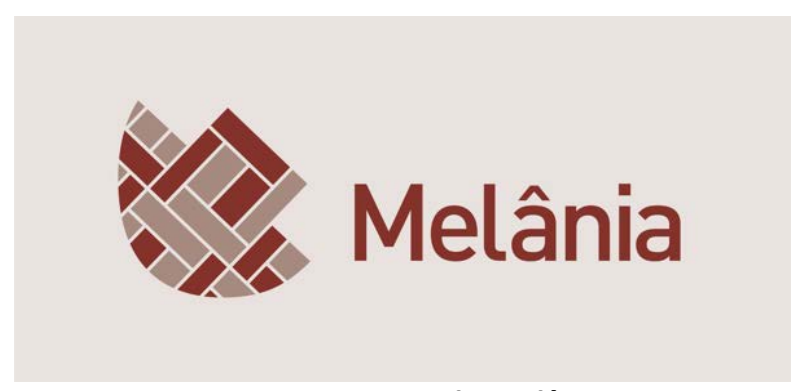

Figura 1 - Marca de Melânia

Fonte: Criação do Estudante 2

Para um terceiro estudante, a cidade "apareceu" em sua imaginação, como se tivesse sido revelada a ele partir da leitura do texto: 
Desde o momento em que li o texto que havia pegado e tive o primeiro contato com Eudóxia, meio que soube que referências procurar, que características iniciais a cidade teria, e consequentemente a identidade visual da mesma, mas criar primeiro essas duas peças me ajudou a reforçar minhas ideia e a encontrar detalhes que viriam a ser utilizados na marca. Desde o principio foi como se a cidade tivesse se erguido diante os meus olhos, com suas cores, cheiros, características, então, construir todo o resto foi como reforçar o traçado daquele esboço inicial que se plantou em minha imaginação. (Estudante 3)

O estudante em questão criou suas peças a partir do texto "As Cidades e o Céu 1", que descreve a cidade de Eudoxia:

Em Eudóxia, que se estende para cima e para baixo, com vielas tortuosas, escadas, becos, casebres, conserva-se um tapete no qual se pode contemplar a verdadeira forma da cidade. À primeira vista, nada é tão pouco parecido com Eudóxia quanto o desenho do tapete, ordenado em figuras simétricas que repetem os próprios motivos com linhas retas e circulares, entrelaçado por agulhadas de cores resplandecentes, cujo alternar de tramas pode ser acompanhado ao longo de toda a urdidura. Mas, ao se deter para observá-lo com atenção, percebe-se que cada ponto do tapete corresponde a um ponto da cidade e que todas as coisas contidas na cidade estão compreendidas no desenho, dispostas segundo as suas verdadeiras relações, as quais se evadem aos olhos distraídos pelo vaivém, pelos enxames, pela multidão (CALVINO, 2003, p.94).

Para representar esta cidade, o estudante criou um universo visual colorido em tons terrosos, com texturas, tipografia e padrões visuais que remetem ao oriente. De acordo com o estudante, um dos elementos que o auxiliou a "construir mentalmente o castelo que seria Eudóxia" foi a direção de arte de um dos seus filmes preferidos: The Fall, dirigido por John Krueger e lançado no ano de 2008. De acordo com a estudante, o universo surrealista do filme, colorido por padrões tipicamente orientais, surgiu na sua mente assim que leu o texto de Calvino pela primeira vez.

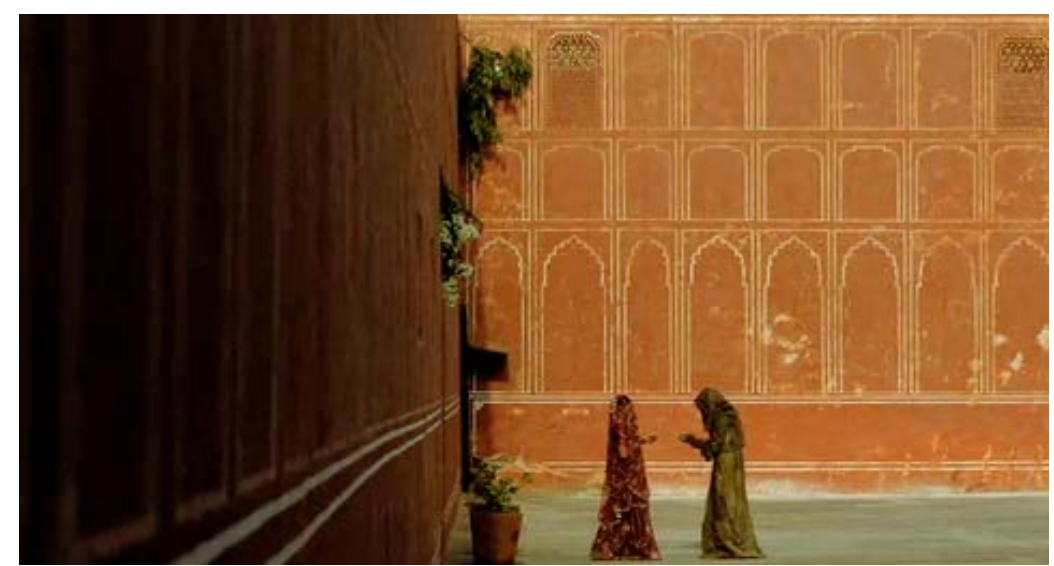

Figura 3 - Cena do filme The Fall

Fonte: http://thefall-locations.blogspot.com.br/

O cartão postal, portanto, procura representar algo que seria uma "vista superior" da cidade, com suas vielas formando um padrão gráfico semelhante a um tapete. Como elemento de onde surge este padrão, o estudante utilizou um desenho 
sintetizado a partir de uma fotografia de uma flor de lótus, planta comumente associada à espiritualidade em diversos países do Oriente. O resultado é um padrão visual ao mesmo tempo sinuoso e estruturado:

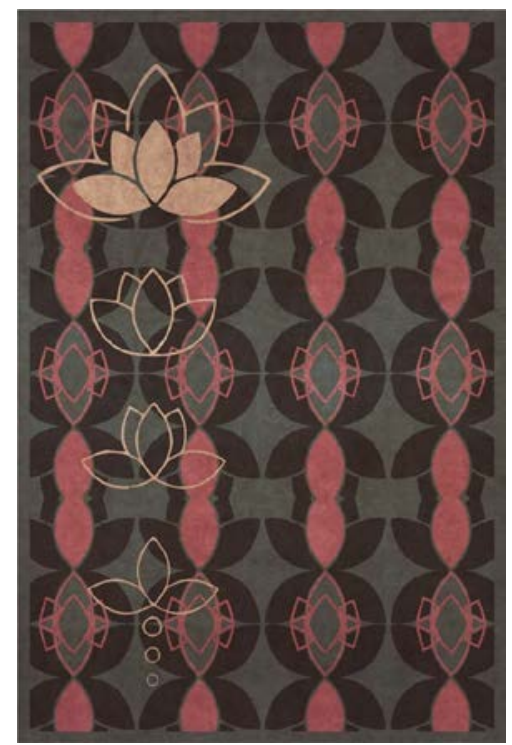

Figura 4 - Cartão postal de Eudóxia Fonte: Criação do Estudante 3.

A marca desenvolvida para a cidade apresenta a mesma flor de lótus, porém deslocada e rebatida a partir de um centro, formando um desenho que assemelha-se tanto à flor que lhe origina quanto a uma mandala.

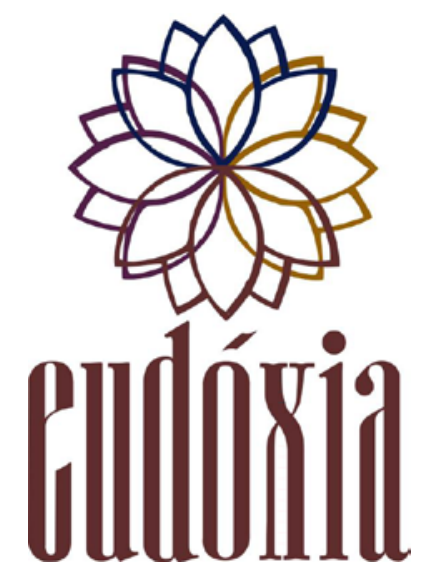

Figura 5 - Marca de Eudóxia

Fonte: Criação do Estudante 3

No processo de acompanhamento deste e de outros trabalhos apresentados, buscou-se garantir que o processo criativo acontecesse livre de amarras conceituais, garantindo que os estudantes estivessem livres para associar, em seu processo, tudo que eles considerassem pertinente como referência. Assim, o processo criativo, neste caso, aproxima-se com a definição que Rolnik faz do pesquisador-cartógrafo como antropófago: 
É tarefa do cartógrafo dar língua aos afetos que pedem passagem. Dele se espera basicamente que esteja mergulhado nas intensidades do seu tempo e que, atento às linguagens que encontre, devore as que the parecem elementos possíveis para a composição das cartografias que se fazem necessárias. O cartógrafo é, antes de tudo, um antropófago (ROLNIK, 2007, p. 23).

Estas referências, estes "afetos que pedem passagem", podem surgir inesperadamente ou serem perseguidos arduamente por alguns. Tal foi o caso do estudante que criou suas peças a partir do texto "As Cidades e o Desejo 4", onde é descrita a cidade de Fedora:

No centro de Fedora, metrópole de pedra cinzenta, há um palácio de metal com uma esfera de vidro em cada cômodo. Dentro de cada esfera, vê-se uma cidade azul que é o modelo para uma outra Fedora. São as formas que a cidade teria podido tomar se por uma razão ou por outra, não tivesse se tornado o que é atualmente. Em todas as épocas, alguém, vendo Fedora tal como era, havia imaginado um modo em transformá-la na cidade ideal, mas, enquanto construía o seu modelo em miniatura, Fedora já não era mais a mesma de antes e o que ate ontem havia sido um possível futuro hoje não passava de um brinquedo numa esfera de vidro (CALVINO, 2003, p.34).

Preocupado em escapar da literalidade de utilizar a esfera de vidro para materializar a cidade em seu cartão postal, o estudante, utilizando como referência o trabalho de Yves Klein, criou uma textura azulada a partir da sobreposição de diversas paisagens de cidades diferentes, inventando, assim, uma Fedora que é a combinação de todas as suas possibilidades.

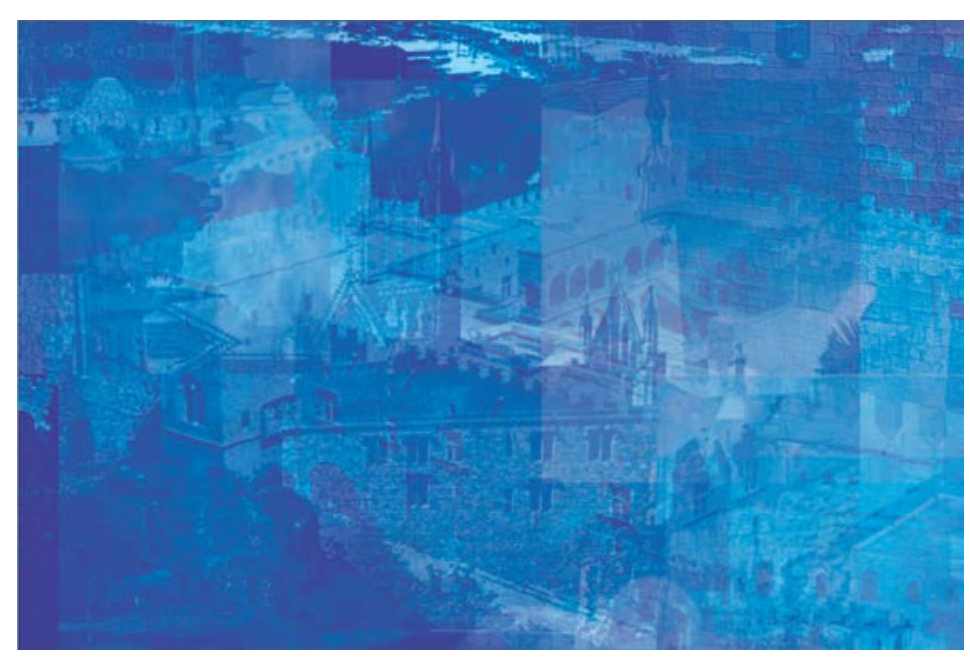

Figura 6 - Cartão postal de Fedora

Fonte: Criação do Estudante 1.

Da mesma forma, o personagem / morador da cidade corporifica-se a partir da sobreposição de diferentes personagens que, embora próximos fisicamente, representam diferentes tempos e modos de ser: 


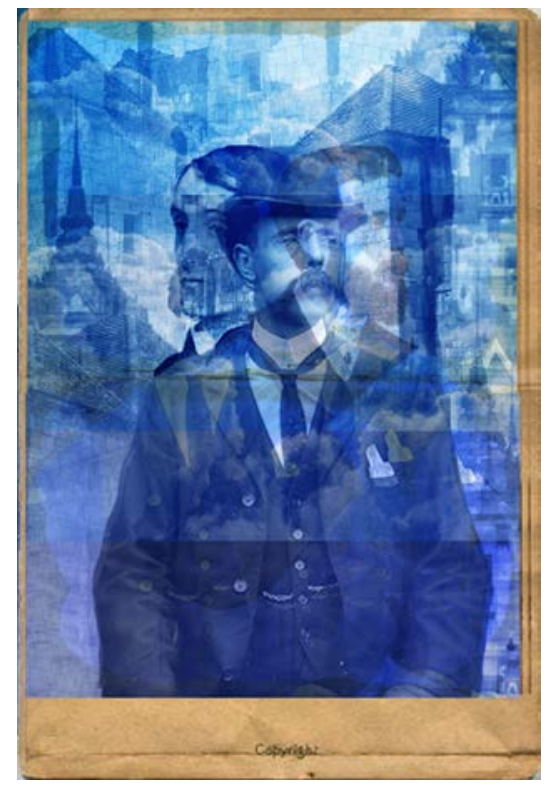

Figura 7 - Morador de Fedora

Fonte: Criação do Estudante 1.

A criatividade, tal como é vista no imaginário contemporâneo, está relacionada a uma espécie de inquietação interior, caracterizada por uma intensidade emocional que parece desconectada e inacessível no cotidiano (mesmo daqueles que atuam em profissões ditas "criativas", muitas vezes sufocados por prazos e demandas irreais). Desta forma, não é de surpreender que a primeira reação dos estudantes, quando confrontados com o tema, tenha sido de certo desconforto.

(este projeto) Foi uma experiência um tanto inusitada. Estávamos acostumados a criar uma marca, uma identidade visual, para uma empresa (ou algo do gênero), e de repente temos que criar algo que parte de uma história fictícia e acaba na identidade visual de uma cidade completamente abstrata. (Estudante 3)

No entanto, o incômodo pelo "trabalhar sem limites" foi logo substituído, em muitos dos estudantes, pela sensação de empoderamento fomentada pela experiência. Em pouco tempo, os estudantes foram capazes de mobilizar seus sentidos, suas experiências e memórias no ato de produzir, criar, inventar.

Enquanto outros projetos do curso de Comunicação Visual do Instituto Federal Sul-Rio-Grandense apresentam exigências e restrições, fechados em um briefing, a ideia de trabalhar com a obra Cidades Invisíveis, durante a disciplina de Laboratório de Criatividade, permitiu o exercício da criatividade de uma forma livre, sem barreiras entre o real e o imaginário. Ao meu ver, foi muito interessante ler sobre uma cidade na qual nunca pisarei e imaginar sua estrutura social, suas características, sua identidade visual. (Estudante 2)

Ao promover esta experiência entre estudantes de um curso técnico em Comunicação Visual, procurou-se pensar na criatividade não como resultado de uma genialidade inacessível ou de condições ideais que não possam ser estimuladas; a criatividade, a habilidade de materializar novos mundos, aparece aqui como a condição de tecer suas próprias relações. 


\section{REFLEXÕES FINAIS}

A diversidade de soluções materializadas pelos estudantes e a riqueza do processo de construção destes trabalhos fazem pensar que a inspiração na literatura pode ser uma alternativa à elaboração de briefings "próximos à realidade" para o desenvolvimento de projetos experimentais. Ao materializar formas a partir de textos literários, os estudantes têm espaço para traçar seus próprios paralelos entre as linguagens verbais e visuais, experimentando um processo criativo que os garante mais espaço onde possam, de fato, criar seus próprios métodos.

Neste contexto, a atitude do professor pode consistir em apresentar os conceitos como uma possibilidade; apenas um olhar entre muitos outros que podem ser construídos a partir do mesmo pensamento. Um conceito, então, seve como uma ferramenta, como instrumentos para produzir novos conhecimentos, novos processos, novos métodos.

Deleuze (2006) diz que "nunca se sabe como uma pessoa aprende; mas, de qualquer forma que aprenda, é sempre por intermédio de signos, perdendo tempo, e não pela assimilação de conteúdos objetivos". Se a contemporaneidade desafia o currículo, lhe impondo certezas e "conteúdos objetivos", ele desafia também o professor, que pode, igualmente, provocá-lo. O currículo pode convocar o professor a criar estratégias de resistência (DELEUZE; GUATTARI, 1997) que possam possibilitar a criação de um espaço/tempo de produção criativa; produção criativa, inclusive, de um ser-professor mutante e nômade.

\section{REFERÊNCIAS}

FAVRETTO, Juliana; MORETTO, Cleide Fátima. Os cursos superiores de tecnologia no contexto de expansão da educação superior no Brasil: a retomada da ênfase na educação profissional . Educ. Soc. [online]. 2013, vol.34, n.123, pp. 407-424.

DELEUZE, Gilles; GUATTARI, Félix. Mil Platôs: capitalismo e esquizofrenia, vol. 5. Tradução: Peter Pál Pelbart e Janice Caiafa. Rio de Janeiro: Ed. 34, 1997.

DELEUZE, Gilles. 0 ato de criação. Trad.: José Marcos Macedo. Palestra de 1978, Edição brasileira: Folha de São Paulo, 27/06/1999, P. 3.

DELEUZE, Gilles. Proust e os signos. Rio de Janeiro: Forense Universitária, 2006.

FERRETTI, Celso João. Formação profissional e reforma do ensino técnico no Brasil: anos 90. Educ. Soc. [online]. 1997, vol.18, n.59, pp. 225-269.

GOMES, Renato Cordeiro. A cidade, a literatura e os estudos culturais: do tema ao problema. Ipotesi - Revista de Estudos Literários. Juiz de Fora, v.3 - n.2, p.17-30, jul./dez. 1999.

OSTROWER, Fayga. Criatividade e processos de criação. Petrópolis: Vozes,1977.

ROLNIK, Suely. Cartografia sentimental: transformações contemporâneas do desejo. Porto Alegre: Sulina: Editora da UFRGS, 2007. 